\title{
De parejas copulantes y representaciones fálicas prehispánicas en la región costarricense
}

Henry O. Vargas Benavides

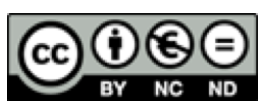

Esta obra está bajo una licencia Creative Commons

Reconocimiento - No comercial-Sin Obra Derivada 

Artículos

\title{
De parejas copulantes y representaciones fálicas prehispánicas en la región costarricense
}

\author{
Henry O. Vargas Benavides \\ Universidad de Costa Rica \\ henry.vargas@ucr.ac.cr
}

Recibido: 16 de enero de 2016 Aprobado:18 de febrero de 2016

\section{Resumen}

En este artículo se analizan los temas de parejas primordiales, parejas cósmicas, dualidades y fertilidad, a través de una comparación desde las teorías del diseño, la semiótica, mitología y la comparatística visual, con énfasis en la simbología y la mitología de la América indígena. Para esto, se toman como base de análisis cuatro objetos arqueológicos de cerámica precolombina pertenecientes a la colección patrimonial del Museo Nacional de Costa Rica, divididos en dos representaciones de parejas copulantes: una de la Subregión Guanacaste y otra de la Región Central, y dos piezas fálicas, ambas de la Subregión Diquís.

Palabras clave: arte precolombino, diseño, diseño precolombino, semiótica, mitología.

\begin{abstract}
This article discusses key pairs, cosmic couples, dualities, and fertility issues through a visual comparison, from the theories of design, semiotics, mythology and the visual Summerfield, with emphasis on the symbolism and mythology of indigenous America. To do so, four artifacts of pre-Columbian pottery belonging to the heritage collection of the National Museum of Costa Rica, are divided into two groups of representations of copulantes couples: one group is composed by one artifact from the Subregion of Guanacaste and one more from the Central Region; and the other collection has two more phallic artifacts of the Subregion of Diquís.
\end{abstract}

Key words: pre-columbian art, design, pre-columbian design, semiotics, mythology. 


\section{Artículos}

\section{Introducción}

El siguiente artículo reúne cuatro objetos arqueológicos de cerámica precolombina pertenecientes a la colección patrimonial del Museo Nacional de Costa Rica, divididos en dos representaciones de parejas copulantes: una de la subregión Guanacaste y otra de la Región Central, y dos piezas fálicas, ambas de la Subregión Diquís. Las piezas se analizan por medio de las teorías del diseño, la simbólica desde la posición de la semiótica, la mitología y la comparatística visual de los objetos. Para lo anterior, se tocarán temas como parejas primordiales, parejas cósmicas, dualidades, signos y símbolos de fertilidad, a través de la comparatística ${ }^{1}$ con representaciones de la América precolombina.

\section{Parejas primordiales}

Desde los aspectos simbólicos de la fuerza creadora se distinguen dos aspectos: la inmanente, en donde la propia materia participa de una energía creadora en una progresión diferenciada de formas, y la trascendente, como una progresión constante de esa misma construcción o creación (Chevalier y Gheerbrant, 2003). En la acción creadora su propia dualidad reside una unidad que es inherente al acto sexual. La relación masculino y femenino se emparenta en los opuestos sol y luna, día y noche, claro y obscuro, donde radica el misterio de los opuestos, en el cual dos seres se unen y representan la polaridad de lo masculino y lo femenino. Si de esa unión resulta "un tercero", ese nuevo elemento resume el hecho o la obra creadora del universo. Esta pareja creadora es la que da origen al cosmos, al multiforme universo (Ronnberg e In Martin, 2011).

Por ejemplo, en la antigüedad griega se distingue la pareja primigenia Zeus y Hera, a pesar de la gran cantidad de amoríos de su esposo; las equivalencias romanas de Júpiter y Juno, ambos representantes del cielo y la tierra; del fresno y el olmo surge la pareja nórdica de Ask y Embla, como pareja primordial; en el occidente de Asia, la pareja Apsu, dios del agua dulce y Tiamat, diosa del agua salada, generan a varios dioses que culminan en Anu, dios del cielo y en Ea, diosa de la tierra y las aguas; los dioses mongoles Qormusta y Sakyamuni (Buda); la pareja japonesa Izanagi (el que invita) e Izanami (la que invita); la pareja africana Aido-Hwedo, masculina y Mawu, femenina, entre otros (Wilkinson, 2009). ${ }^{2}$

La relación clave de cielo con fecundidad orienta el modelo de pensamiento cósmico en los distintos sistemas de creencias alrededor del mundo. La fecundidad comprende

\footnotetext{
${ }^{1}$ Ver Lotman, I. (1996).

${ }^{2}$ Se citan tan sólo algunos ejemplos de parejas o deidades creadoras, pues en otros casos los mitos de la creación provienen de una sola fuerza creadora como Ra en el antiguo Egipto o de triadas fundamentales como en el caso de la mitología védica de Brahma, Vishnú y Shiva.
} 
entonces una extensión amplia indicada por Mircea Eliade (1995) como "luna-aguas-mujer-tierra”. Por tanto, la relación celeste con una diosa no es meramente celeste sino la aseguradora del ciclo de la vida, por eso:

Los dioses meteorológicos (rayo, tormenta, lluvia) y genésicos (el toro) pierden su autonomía celeste, su soberanía absoluta. Cada uno de ellos es acompañado, y a menudo dominado por una diosa, de la que depende en última instancia la fecundidad universal. Ya no son creadores cosmogónicos, como las divinidades celestes primordiales, sino fecundadores y procreadores del orden biológico. La hierogamia se convierte en función esencial. (p. 105 )

De acuerdo con lo anterior, las parejas divinas son las que regulan el orden de los seres humanos que habitan la tierra y establecen distintas reglas propias de cada acción y grupo en su diversidad de culturas.

Entre las versiones de la mitología incaica, el dios sol Inti coloca al pueblo originario a orillas del lago Titicaca liderados por Manco Cápac, quien tenía tres hermanos y hermanas; una de ellas fue Mama Ocllo, las cual se convirtió en su esposa ${ }^{3}$. Lo trascendente es que de esta pareja real surgen los posteriores gobernantes del resto del grupo y las diversas clases de campesinos y esclavos que desarrollan el imperio o el pueblo del sol (Wilkinson, 2009, p. 314). Por esta razón, el origen se sitúa en el nacimiento de un pueblo que trasciende hasta convertirse en un imperio, en donde el esposo, representante del sol, recibe la orden divina de viajar portando una vara de oro que debe clavar cada vez que se detengan a descansar o a comer y en el lugar donde se hunda completamente el cayado, será la señal de un suelo profundo y fértil; ese sitio fue Cuzco, donde inicia la dinastía incaica bajo el liderato de Manco Cápac y su esposa Mama Ocllo.

El fenómeno vivido por esta pareja - uno como el sol, simbólico de arriba y la otra de la tierra, de abajo -, además de la vara y el suelo, es la representación íntima de la unión de la pareja y del desarrollo de cientos de siglos de conocimiento que culminan en el sistema agrícola. La tacna o palo de siembra, utilizado por los incas en la agricultura, asemeja a un bastón con forma de mango o empuñadura y cerca de la base un soporte para ser clavado con el pie. Esto supone siglos de conocimiento que terminaron en el desarrollo del sistema agrícola en los terrenos agrestes de las costas peruanas, con el cual se domesticaron plantas como maíz, frijol, yuca, calabazas, papas, básicas en su dieta y otras semidomesticadas o aprovechadas para la simple recolección (Vergara en Ardón, 1993, pp. 35-36, 72-73).

El texto más cercano al concepto creador indígena se encuentra resumido en el Popol Vuh, manuscrito de Chichicastenango dado a conocer a inicios del siglo XVIII, en donde se resume el origen de los pueblos de esta región mayense. En primer lugar, el concepto

\footnotetext{
${ }^{3}$ En otras de las versiones esta primera descendencia surge de una cueva.
} 


\section{Artículos}

del creador reside en una sola deidad que asume el papel de madre y padre, al que se le denomina creador y formador, el cual mantiene la armonía del cosmos, del cielo, la tierra y el agua. A partir de su voz, como elemento catalizador, aparecen los señores Tepew y K'ucumatz, personajes que dan origen al resto de la vida. El texto lo resume así:

Antes de la Creación no había hombres, ni animales, pájaros, pescados, cangrejos, árboles, piedras, hoyos, barrancos, paja ni bejucos y no se manifestaba la faz de la Tierra; el mar estaba suspenso y en el cielo no había cosa alguna que hiciera ruido. No había cosa en orden, cosa que tuviese ser, si no es el mar y el agua que estaban en calma y así todo estaba en silencio y obscuridad como la noche.

Solamente estaba el Señor y Creador, K'ucumatz, Madre y Padre de todos lo que hay en el agua, llamado también Corazón del Cielo porque estaba en él y en él reside. Vino su palabra acompañada de los señores Tepew y K'ucumatz y, confiriendo, consultando y teniendo consejo entre sí en medio de aquella obscuridad, se crearon todas las criaturas. (Saravia, 1996, p.16)

De esta pareja formadora continuará otra en el relato que concluirá con lo establecido por sus predecesores en el cuadrante de la tierra y su ordenamiento, en el supramundo e inframundo; esta pareja serán los hermanos Juanajpú e Xbalamqué. Ellos pasan por una serie de pruebas y enfrentamientos con lo que dictan pautas fundamentales para el pueblo maya quiché. Los hermanos son capaces de enfrentar a los Ajabab de Xibalbá o los señores del inframundo. Su relación de héroes culturales les permite concluir parte importante de su universo al convertirse en los astros principales para la tierra. Así lo reza el relato:

Junajpú e Xbalamqué, después de haber vencido a los Ajawab de Xibalbá, subieron hacia el Cielo y el uno fue puesto por el Sol y el otro por la Luna, subiendo también los cuatrocientos muchachos que mató Zipacná, los que fueron puestos por estrellas (Ibidem, p. 136).

En tres de los templos de la Cruz de Palenque se narra, tanto en el escritura como en la iconografía, el origen de la creación del mundo. El padre y la madre primordiales preceden la denominada época actual; a ellos les antecede la diosa Itzamnaaj, a quien se le asigna el cargo de divinidad suprema en el panteón maya. En una de las tablas del Templo de la Cruz, del año 692 d.C. se representa en su centro al árbol del mundo que brota de un recipiente y en su cúspide yace Itzamnaaj, en forma de gran ave de amplio plumaje (Wagner, 2006, pp. 281-282).

Para los nicaraos, de acuerdo a los registros de Francisco Bobadilla mencionados por Oviedo, la pareja fundamental son Tamagastat y Cipattonal. Ellos son los responsables de crear el mundo y son los que resguardan desde el supramundo toda su creación. Así lo transcribe Samuel Kirkland Lothrop (2004):

El mundo fue creado por Tamagastat (Tamagostat) y su mujer Cipattonal (Cipaltoval), ayudados por Ochomogo, Calchitguegue y Chicociagat. No sólo el mundo fue creado por esa divina pareja, sino 
también ellos son los responsables de la recreación después del diluvio, «y toda la raza de los hombres y mujeres desciende de ellos». En tiempos primitivos Tamagastat y Cipattonal moraban en la tierra, en forma de indios, donde se dice que diseminaron la cultura que disfruta la humanidad. Más tarde subieron al cielo (que es el lugar donde el sol se levanta), y allí son los gobernadores de un paraíso, a quienes sirven las almas de aquellos que caen en batalla. Así pues, esta pareja celestial gozaba de tres atributos: eran deidades creadoras, héroes de la cultura y dioses que gobiernan el cielo. (p. 85)

\section{Otras dualidades en la simbólica indígena}

En las diversas representaciones míticas alrededor del orbe subyace la representación de componentes que encierran los principios completos del universo, compuestas por fuerzas contrarias y de unidad. Este binomio de fuerzas, de dualidades, lo enmarca Juan Eduardo Cirlot (1992) como:

La integración de esa contradicción en un complejo superior origina un sistema binario, fundado en la tensión de una polaridad. A veces, las dos fases son simétricas, es decir, de fuerza y extensión equivalentes; pero en otras ocasiones, la diferencia es dada por relaciones irregulares. Los fenómenos cósmicos; día, noche; invierno, verano; crecimiento, decrecimiento; vida, muerte; sístole, diástole; inspiración, espiración; juventud, vejez; de carácter sucesivo valen para el caso como los pares de contrarios que pueden ser sucesivos o simultáneos, cual: húmedo, seco; frío, cálido; masculino, femenino; positivo, negativo; sol, luna; oro, plata ; redondo, cuadrado ; fuego, agua ; volátil, fijo; espiritual, corpóreo ; hermano, hermana, etc., y se hallan en el caso. (p.109)

En una de las representaciones de parejas copulantes pertenecientes a la colección del Museo Nacional de Costa Rica se observa a una pareja de la Región Central del país en su cópula amorosa (Fig. MNCR B345).

\section{Figura 1}

MNCR B345, Pareja copulante, vista lateral, 8,2 x 4 x 5,8 cm, 1-700 d.C., Valle Central

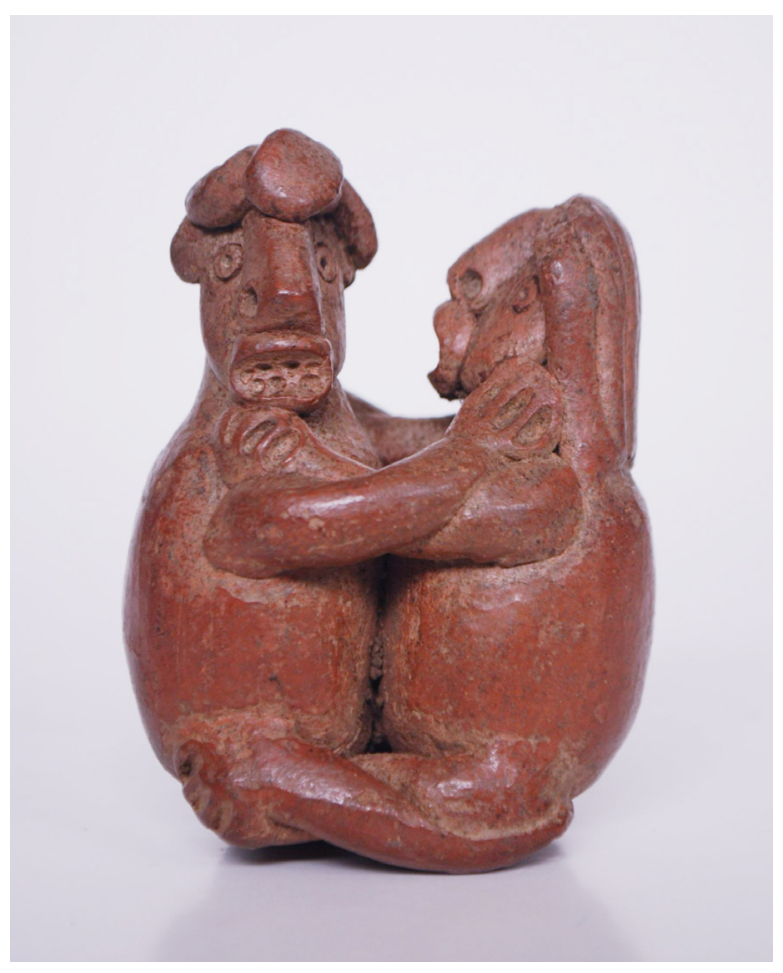

Fotografía por Diego Herrera Quirós 


\section{Figura 2}

MNCR B345, Pareja copulante, vista lateral opuesta, $8,2 \times 4 \times 5,8$ cm, 1-700 d.C., Valle Central

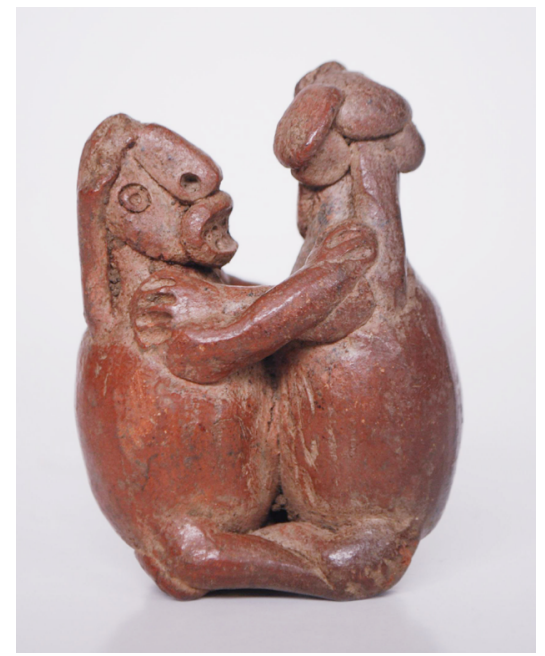

Figura 3

MNCR B345, Pareja copulante, vista de tres cuartos, $8,2 \times 4 \times$ $5,8 \mathrm{~cm}, 1-700$ d.C., Valle Central

\section{Figura 4}

MNCR B345, Pareja copulante, vista inferior, $8,2 \times 4 \times 5,8 \mathrm{~cm}$, 1-700 d.C., Valle Central
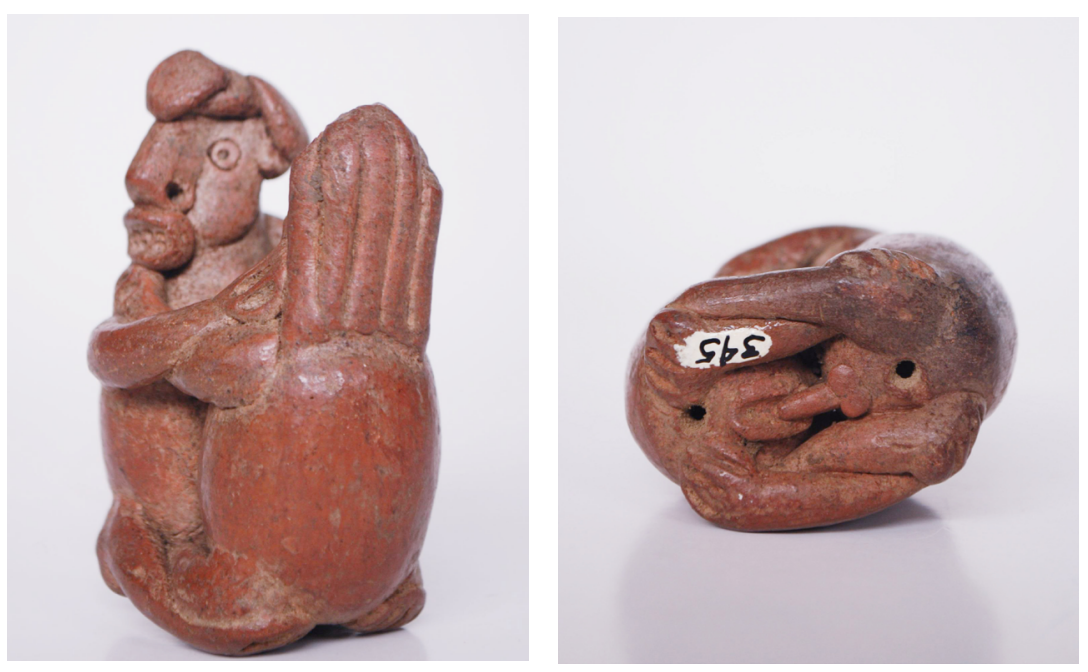

Fotografía por Diego Herrera Quirós

De forma sutil, la figura entrelaza los brazos y piernas entre sí, se encuentran sedentes y mientras que la figura femenina mira a su par, el otro mira hacia un costado. Es una figura cerámica monocroma, en donde sus cuerpos se han estilizado de manera que lucen cual jícaras o robustas frutas; esta es la base donde luego se le incorporaron los demás elementos en la arcilla cruda. Detalles del cabello o tocados, así como cabeza, piernas, brazos, boca, entre otros, han sido amasados y unidos por aparte y luego acoplados. Los ojos, dedos, dientes y fosas nasales se diseñaron a través de un instrumento de punta para provocar texturas de punzado o surcos. Las narices de ambos son rectas y anchas a la vez. En la figura masculina se observa un tocado, mientras que la femenina y cabello largo caído hacia atrás. Por otra parte, en la vista inferior, se representa claramente ambos órganos sexuales: el femenino y el masculino en plena acción coital. A continuación, obsérvese las distintas vistas de la pieza y los detalles mencionados.

Paul Westheim (1988), al analizar el arte precolombino en México y alrededores, indica que la dualidad es parte de la concepción de las deidades, la naturaleza y el arte. El enigma cósmico se fundamenta en fuerzas antagónicas. Es importante recordar que el principio constructivo en donde el orden piramidal se divide en una principal representante del sol y la siguiente representante de la luna. 


\section{Figura 4}

MNCR 24067, Pareja copulante, vista lateral, $18,1 \times 8,5 \times 14,7 \mathrm{~cm}, 300-500$ d.C.

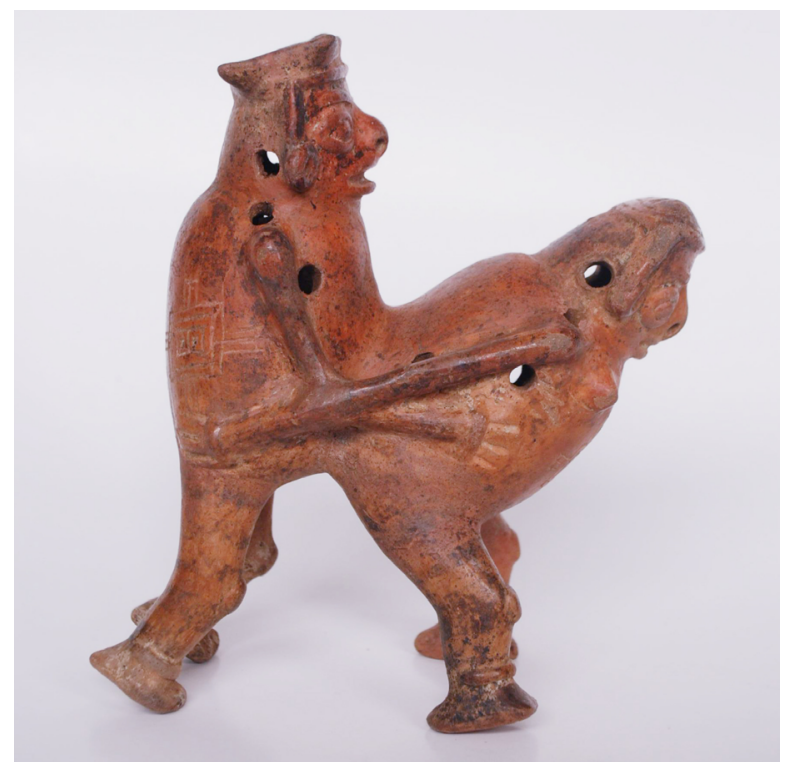

En la siguiente representación de pareja de la Subregión Guanacaste (Fig. 24067) las figuras simbolizan la cópula sexual de pie. La figura femenina se encuentra de espalda, con rodillas reclinadas, espalda echada hacia adelante y los brazos se apoyan hacia la espalda de la otra figura. Mientras tanto, la figura masculina, casi en posición vertical -salvo un pequeño movimiento provocado por el levantamiento de los tobillos del plano horizontal - entrelaza los brazos hacia las caderas de la figura femenina. A diferencia de la anterior representación, las cabezas son más achatadas, en forma rectangular y ambos personajes llevan vinchas; el tocado del hombre se levanta a los extremos como un rectángulo, mientras que el de la mujer lleva una decoración geométrica y de forma

\section{Figura 5}

MNCR 24067, Pareja copulante, vista frontal, $18,1 \times 8,5$ $\mathrm{x} 14,7 \mathrm{~cm}, 300-500 \mathrm{~d} . \mathrm{C}$.

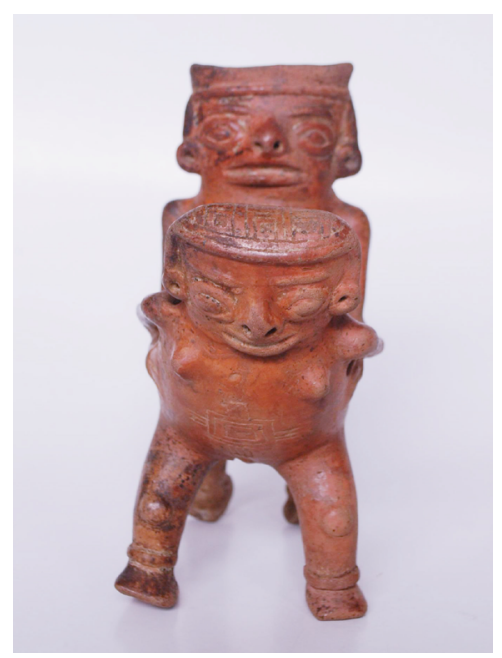

Figura 6

MNCR 24067, Pareja copulante, vista de atrás, 18,1 x 8,5 $x$ 14,7 cm, 300-500 d.C.

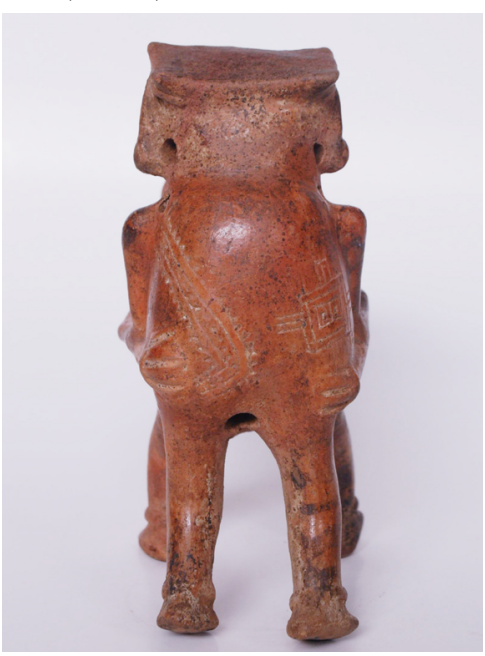

Figura 7

MNCR 24067, Pareja copulante, vista inferior, $18,1 \times 8,5$ $\mathrm{x} 14,7 \mathrm{~cm}, 300-500$ d.C.

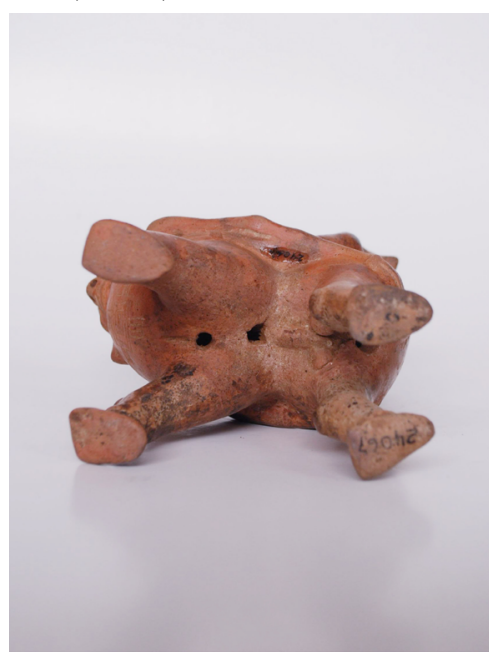

Fotografía por Diego Herrera Quirós 


\section{Artículos}

ovalada. Las dos figuras portan alrededor del cuerpo una especie de faja cruzada lateralmente en el cuerpo. Cejas, ojos y boca, lucen alargadas y con sutil relieve, mientras que las narices son respingadas. Como accesorios, ambos portan orejeras, brazaletes en brazos y piernas, así como rodillas y pechos que sobresalen por sus relieves.

Es apenas de notar que las figuras tuvieron pigmento oscuro, el cual se nota con más precisión en forma de anillos alrededor de las piernas de ambos. Por la zona inferior apenas se perciben los órganos masculino y femenino, en esa misma acción coital. La pieza posee varios agujeros que apunta a un uso de colgante o similar, como función dentro de su contexto. Obsérvense varias vistas de lo mencionado:

Oviedo, mencionado por Samuel Kirkland Lothrop (2004), verifica que en los pueblos nicaraos" "Sus matrimonios son de muchas maneras"; asimismo, apunta Oviedo (lib. XLII, cap. I): "e hay bien que decir en ellos, e comúnmente cada uno tiene solo una muger, e pocos son los que tienen más, excepto los principales o el que puede dar de comer a más mugeres; e los caciques cuantas quieren" (p. 75).

En la pareja copulante de la Subregión Guanacaste, se representa un signo, tanto a un costado de la espalda de la figura masculina, como en el estómago de la figura femenina, un cuadrado conteniendo otros dos y cuatro puntas dobles dirigidas hacia afuera en cada uno de sus lados. No obstante, existe una sutil diferencia entre la representación de la forma en la figura masculina y la femenina, en donde la masculina, el cuadrado central se divide en dos y, en la femenina, se encuentra completamente unido y las cintas inferiores son tres en lugar de dos como en el resto.

\section{Figura 9}

Forma geométrica representada en la espalda del personaje masculino

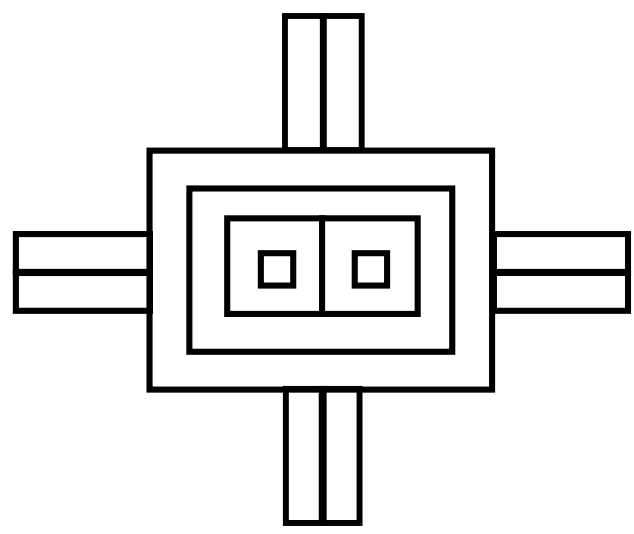

Fuente: Henry Vargas

Figura 10

Forma geométrica representada en la espalda del personaje femenino

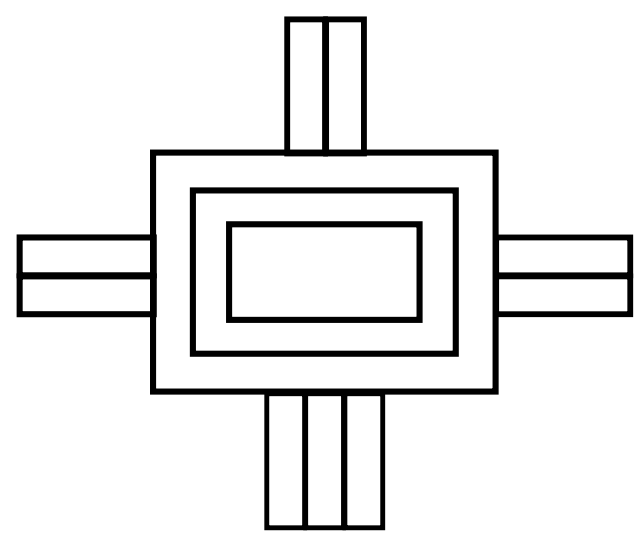

Fuente: Henry Vargas 
A continuación cada una de estas formas:

En otro de sus textos Paul Westheim (1987) analiza el signo Ollin como representación de los cuatro puntos cardinales y un ojo en su centro o intersección. Este es el Nahui Ollin o el sol que asciende y desciende del firmamento y también del movimiento, signo que concibe la complementariedad de día y noche; claro y oscuro; mundo superior y mundo inferior (p. 154). Semejante distribución parece en los cuadrados de las figuras masculina y femenina de Guanacaste. La sutil diferencia encontrada en ambas figuras representadas de esa pareja enfatiza los opuestos femenino, masculino, vida y muerte en la cópula sexual. En el signo Ollin (tomado del códice de Borgia) se aprecia también la estructura que se divide en cuatro puntos al partir de su centro. Además del empleo de tonos contrastantes, el amarillo y el rojo.

En la figura anterior, ambos signos encontrados clarifican la composición del cosmos en ambos elementos geométricos, en donde la línea estructural horizontal y la vertical dirigen la posición sagrada del universo representado, sea por puntos cardinales, sea por los cuatro vientos y luego, en color rojo, el remate de líneas diagonales que dirigen hacia otras cuatro direcciones sagradas del signo.

En el universo maya, la relación simbólica de las ciudades, plazas y pirámides representan ese orden cósmico y, a la vez, el reflejo del mundo de los dioses. Ese modelo está dividido en los cuatro cuadrantes o puntos cósmicos, en cuatro árboles y al centro un nudo
Figura 11

Signo Ollin, Calco (Vargas, 2016)

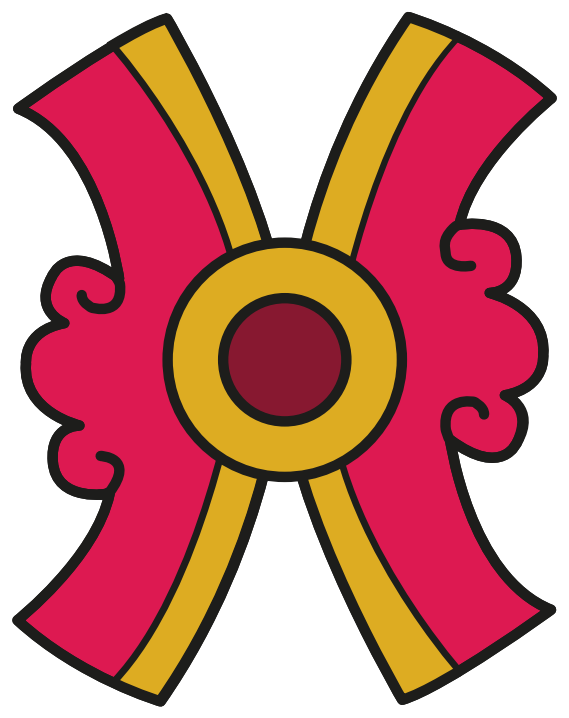

Fuente: Códice de Borgia

Figura 12

Estructura del signo Ollin, (Vargas, 2016)

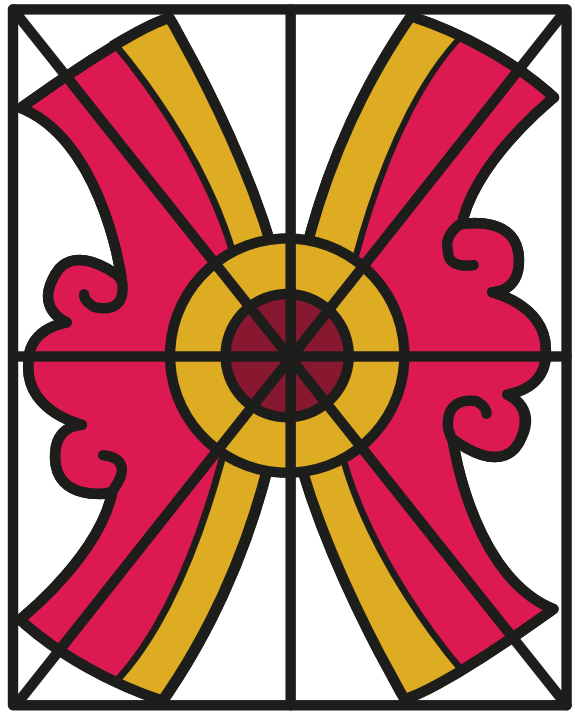

Fuente: Códice de Borgia 


\section{Artículos}

\section{Figura 13}

Estructura del signo representado en la figura masculina MNCR 24067

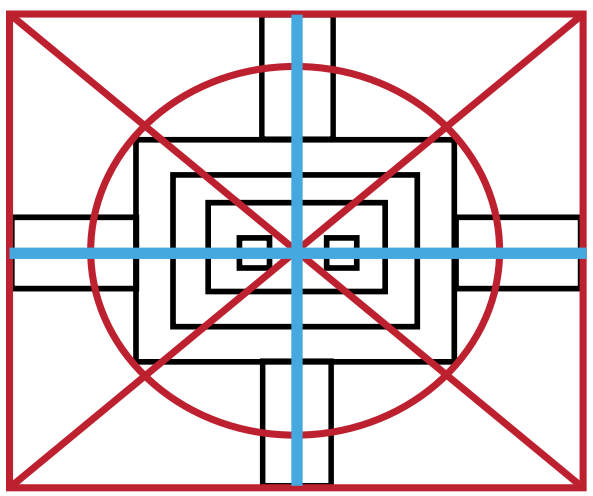

Fuente: Henry Vargas

\section{Figura 14}

Estructura del signo representado en la figura femenina MNCR 24067

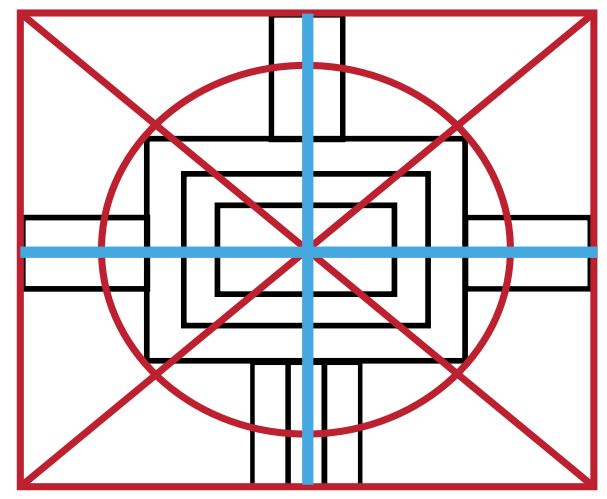

Fuente: Henry Vargas

o anillo que amarra el todo, el quinto punto cósmico. Lo anterior también se menciona en los relatos del Popol Vuh y del Chilam Balam de Chumayel. Sea una sola deidad creadora o la pareja primordial, luego de creado el universo, este se ordena y se distribuye en estos cuatro puntos sagrados. Elisabeth Wagner
(2006, op. cit) hace referencia al ordenamiento del cosmos maya de la siguiente forma:

Las plazas, pirámides, templos y palacios imitaban bajo formas simbólicas el paisaje mítico configurado por los dioses el día de su creación. Y así, cada vez que construía un edificio o se medía un terreno con una cuerda, se repetía y confirmaba aquel acto mítico. (p. 289)

La misma casa es la representación de la creación y su universo, en donde el binomio, dentro fuera; oscuridad, luz; femenino, masculino; arriba, abajo; Sibö, Surá; supramundo, inframundo; condensan también los pares opuestos. Este principio equivale a la construcción y representación de las casas en las culturas bribri y cabécar de Costa Rica (González y González, 1989).

\section{El falo y asociaciones con ritos de fertilidad}

En la India, el árbol se asocia con el bejuco que, a su vez, representa al dios Shiva en forma de linga. En occidente este es símbolo de la fecundidad humana y animal representada en Dionisos. Al desdoblar la pareja o díada, surgen opuestos como "el falo y el huevo, la luz y las tinieblas, el cielo y la tierra, el yin y el yang", entre otros, y es posible agregar el signo Ollin, como ya se indicó. El árbol, columna, designa elementos cargados de la energía masculina que se equilibran sobre el horizonte, suelo o la contraparte femenina (Chevalier, 2003). Es también símbolo de la procreación, del principio activo, de 
perpetuación de la vida y fuerza de propagación cósmica (Cirlot, 2008).

Chevalier (op. cit.) también amplía que el elemento lluvia en la América precolombina mantiene una relación directa con el dios de la lluvia, Tlaloc. Así, en la hierogamia cielo-tierra, la lluvia representa el esperma que fecunda el suelo, propio de las tradiciones agrarias. Palabras como esperma, simiente, sangre, resina o savia, son similares; por tanto, muchos de estos rituales se combinan con sacrificios humanos o de animales. El rayo y el relámpago son afines a los dioses de las tormentas; en la mitología bribri, el rayo se emparenta con la serpiente y, a la vez, la serpiente con el bastón o Shulakàma y el pene (Stuart, 1995, p. 13) (Jara y García, 2003).

En el área de la denominada Mesoamérica, el culto a lo fálico se identifica con los rituales agrícolas en donde la tierra recibe abundantes precipitaciones para las siembras, como lo explica Carlos Navarrete en su artículo (2010). Existe también la práctica de la perforación o mutilación del pene en donde la sangre fecunda la tierra. A lo largo de esta área concurren diversas representaciones de figuras de masturbadores, representaciones fálicas (abundantes en la zona de Yucatán), así como otras representaciones en cuevas, del Señor de la Tierra y la simbólica de aguas subterráneas. En el caso del área costarricense, el Museo del Jade cuenta con una importante colección de representaciones de falos que deben retomarse para futuros trabajos.
De forma similar, en las crónicas de Oviedo descritas por Samuel Kirkland Lothrop (2004), los nicaraos realizaron el sacrificio de sangre como ofrenda y el sacrificio de la fertilidad de la tierra. Así lo expresa esta síntesis del relato:

También semejante al mexicano fue el rito nicaragüense de ofrecer sangre sacada de la lengua, orejas o pene. Como en México, esta ofrenda se consideraba cuestión de todos los días, y Pedro Mártir nos dice que los aborígenes poseían un polvo que curaba en pocas horas la heridas causadas de esta manera. (p. 95)

En la Subregión Diquís, ubicado hacia el sur del actual territorio costarricense, existen representaciones femeninas y masculinas de fuerte estilización, en donde el órgano sexual femenino es representado por una curvatura o forma de concha o arco (Fig. MNCR 24087) mientas que la representación masculina se simboliza mediante un sinuoso relieve de dos esferas y una línea gruesa hacia arriba o el falo en plena erección(Fig. MNCR 14592). En algunos casos, una mano roza el órgano sutilmente y la otra mano, en dirección hacia arriba, como insinuando un cierto placer (Fig. MNCR 24176). ${ }^{4}$

De esta misma sociedad de Diquís, el Museo Nacional alberga dos pequeñas vasijas con falo de pequeño formato. En la primera -MNCR 21336- su representación fálica está un poco desgastada en su cabeza y en el borde superior de la vasija; en la segunda

${ }^{4}$ Cfr. estas piezas en el libro de Vargas (2015), Diseño precolombino en Costa Rica, Capítulo primero. 


\section{Artículos}

\section{Figura 15}

MNCR 21336. Vista de tres cuartos, Vasija con falo como personaje, 7,6 x $4 \times 5,5 \mathrm{~cm}$, 1000 - 1550 d.C., Diquís

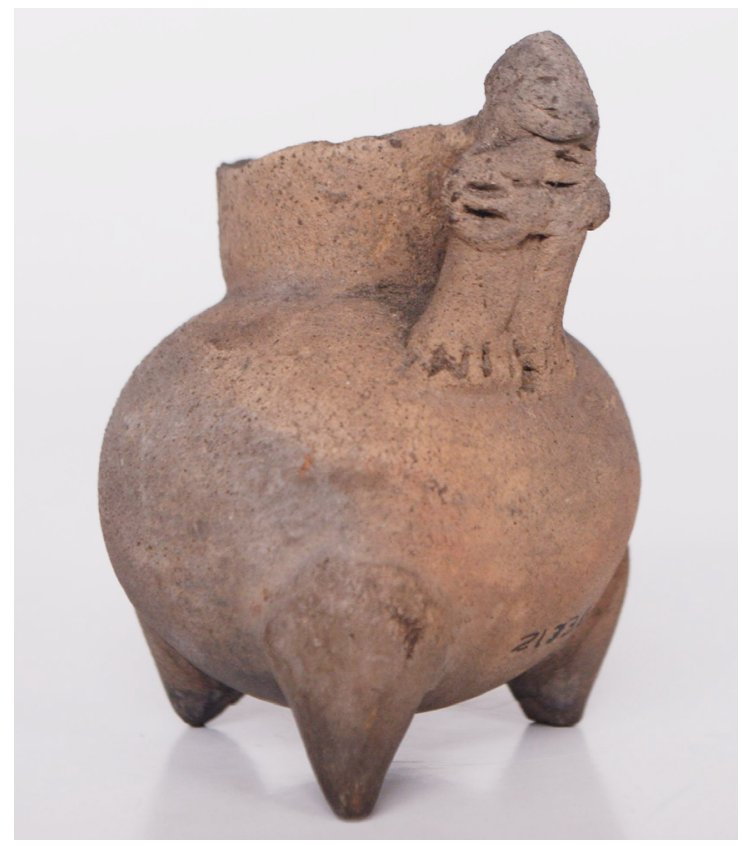

-MNCR 12719- la forma se encuentra casi intacta. En ambas, la representación fálica se convierte en un personaje puesto que en la primera es un personaje de pie, con los brazos cruzados en forma horizontal y claramente los pies hacia el frente, mientras que en la segunda, de manera clara, el glande se convierte en el sombrero del personaje que también está de pie; este posee orejas, nariz y ojos en forma de semillas y boca alargada, pero lo más curioso es su sonrisa que tapa con la mano izquierda, mientras que la otra mano se dirige hacia la barriga o a la representación metatextual de su mismo órgano.

Son pocas las representaciones precolombinas que denotan una sonrisa en las piezas, como es el caso de las figuras Totonacas en Veracruz, México. En las piezas del Museo Nacional de Costa Rica, se observa cómo a la representación del falo se le adhiere brazos,

\section{Figuras 16, 17 y 18}

MNCR 21336. Vistas lateral, superior e inferior, Vasija con falo como personaje, 7,6 x 4 x 5,5 cm, 1000 - 1550 d.C., Diquís
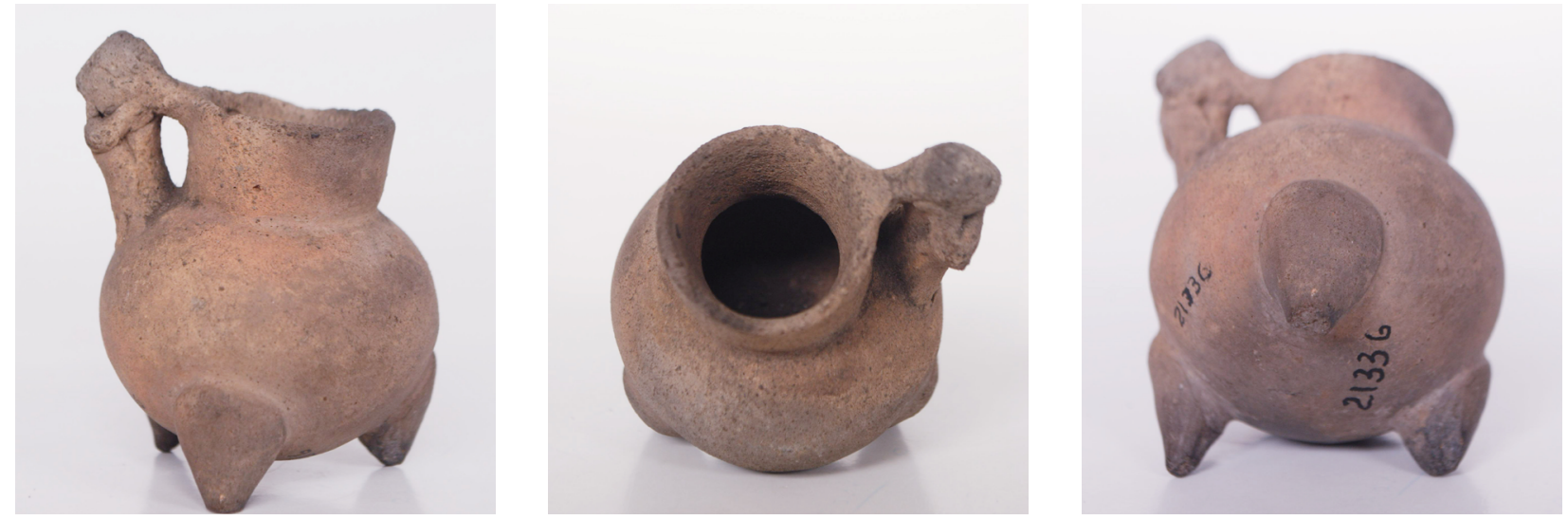

Fotografías por Diego Herrera Quirós 


\section{Figura 19}

MNCR 12719. Vista del falo como personaje de frente, 6,6 x 5,4 x 7,9, 1000-1550 d.C. Diquís

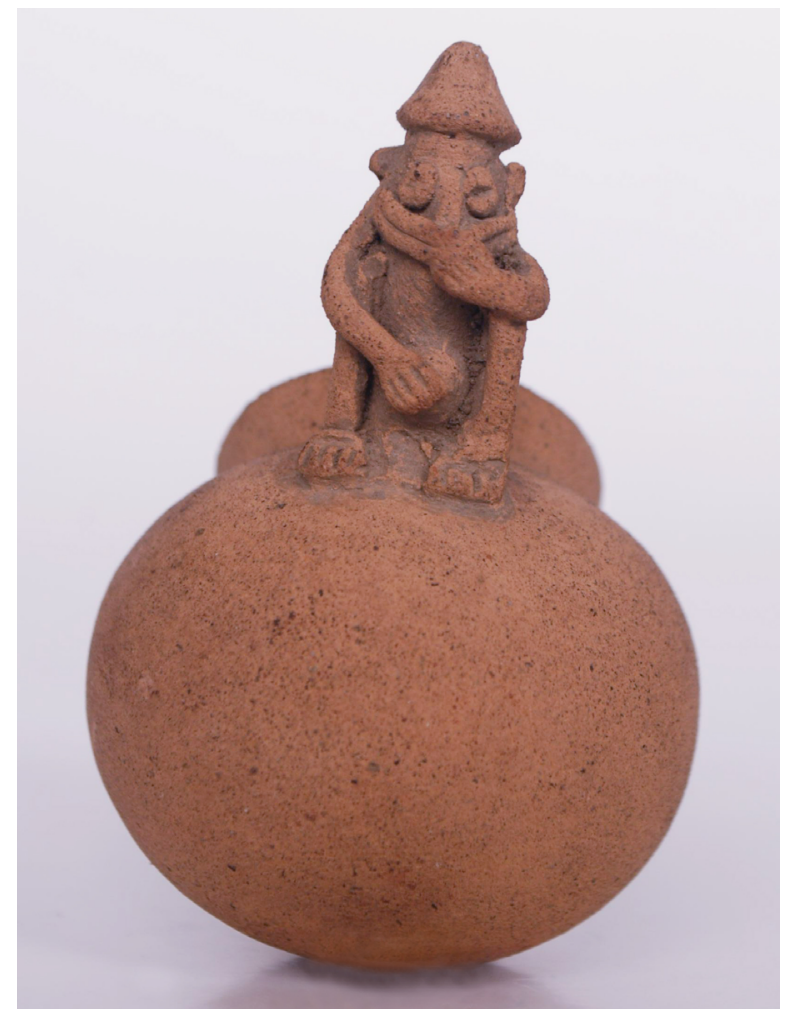

piernas y demás expresiones como en la segunda figura. Obsérvese distintas vistas de cada una de las dos piezas cerámicas:

\section{Conclusiones}

Entablar un diálogo y análisis sobre este tema, merece que en un futuro cercano se pueda hacer una ampliación necesaria del

\section{Figura 19}

MNCR 12719. Vista de frente, $6,6 \times 5,4 \times 7,9$, 1000-1550 d.C. Diquís

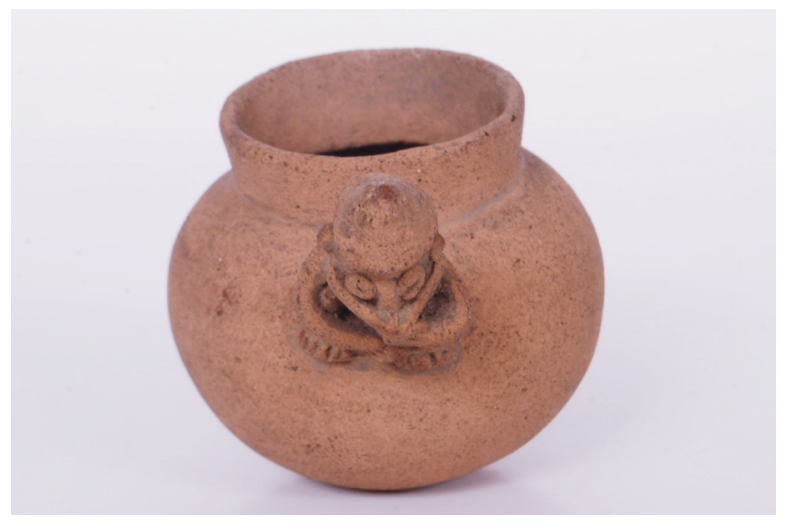

Figura 21 y 22

MNCR 12719. Vista lateral y superior, 6,6 x 5,4 x 7,9, 1000-1550 d.C. Diquís
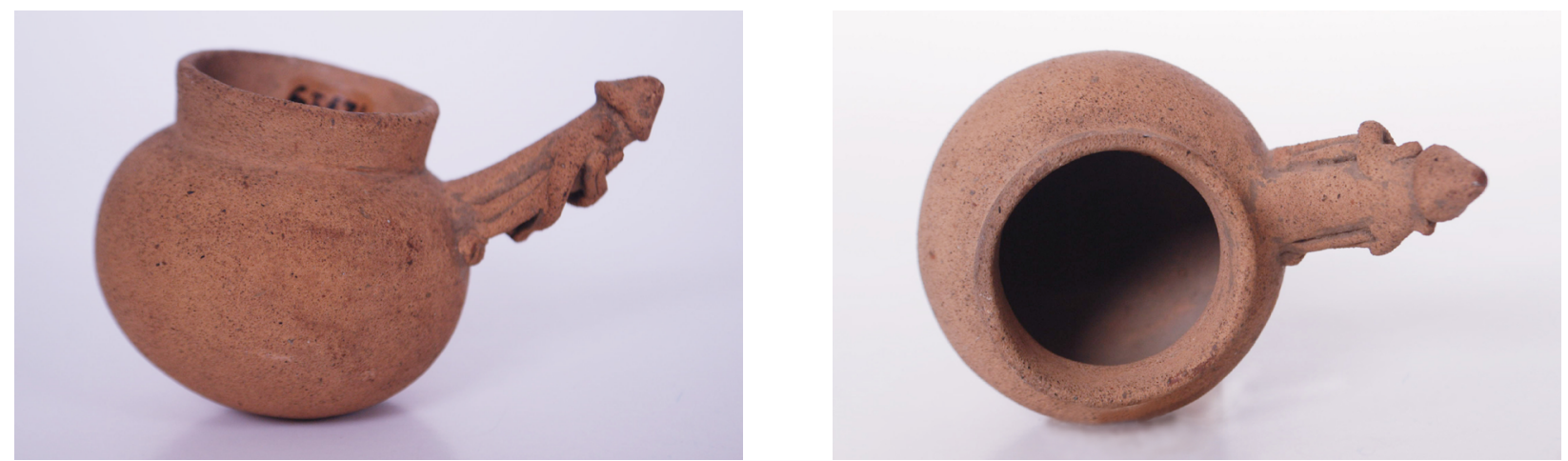

Fotografías por Diego Herrera Quirós 


\section{Artículos}

corpus para comprender mejor las representaciones eróticas, de fertilidad o similares, de las colecciones de museos como el de Jade, en Costa Rica. Esta institución posee una rica representación, en su mayoría cerámica de representaciones fálicas o afines (mujeres embarazadas, personajes masturbadores, parejas copulantes, falos con base para superficie, falos con agujeros para colgar, flautas, pitos, vasijas antropomorfas sobre la fertilidad masculina y femenina, entre otras), piezas que se encuentran exhibidas en la "Sala de la memoria".

Se hace más que necesario analizar otras muestras de objetos sobre el tema de la fertilidad desde perspectivas del arte y diseño, la relación simbólica de las mismas, así como otras visiones comparativas desde las perspectivas inter y transdisciplinarias. Estas discusiones pueden abrir las puertas hacia nuevos aportes sustanciales para una mejor comprensión de la sacralidad o no de las culturas prehispánicas. Es pertinente que las políticas sobre interculturalidad de los centros de enseñanza costarricenses y latinoamericanos acojan estos temas, en donde se abarquen las diferencias socioculturales que poseemos, que nos distinguen como individuos y como grupos humanos. El estudiantado debe ser capaz de comprender el fundamento simbólico de los pueblos indígenas hacia una comprensión y totalidad del cosmos, en relación armónica y respetuosa con el medio ambiente, la madre tierra, el agua y demás seres que habitamos el planeta.
La visión de la comparatística visual debe ampliarse por medio de bases de datos de objetos artísticos de las distintas culturas en nuestro continente, sean indígenas, de tradición occidental, o de otras culturas con las que hoy en día compartimos. Esto permitiría ampliar discusiones desde el plano de la interculturalidad y el medio ambiente al que pertenecemos.

\section{Referencias}

Chevalier, J. y Gheerbrant, A. (2003). Diccionario de los símbolos. Barcelona: Herder.

Cirlot, J. (2008). Diccionario de símbolos. Barcelona: Siruela.

González, A. y González, F. (1994). La casa cósmica talamanqueña y sus simbolismos. San José: EUNED y EUCR.

Jara, C. y García. A. (2003). Diccionario de la mitología bribri. San José: EUCR.

Lothrop, S. et al. (2004). Cultura indigenas de Nicaragua, tomo I. Managua: HISPAMER.

Lotman, I. (1996). La Semiosfera I. Semiótica de la cultura y del texto. Madrid, España: Ediciones Cátedra, S.A.

Navarrete, C. (2010). Acercamiento a la masturbación ritual en Mesoamérica. Arqueología mexicana. Consejo Nacional para la Cultura y las Artes. Instituto Nacional de Antropología e Historia,18(104): 46-50. 
Ronnberg, A. y In Martin, K. (2011). El libro de los símbolos: Reflexiones sobre las imágenes arquetípicas. Koln: Taschen.

Saravia, A. (1996). Popol Vuh. Antiguas historias de los mayas k'ichee's de Guatemala. Guatemala: Piedra Santa.

Stuart, R. (1995). Bribris. Semillas de Sibö. San José: ICER.

Vergara, R. En: Ardón, M. (1993). Agricultura prehispánica y colonial. Tegucigalpa: Guaymuras.
Wagner, E. En: Grube, N., Eggebrecht, E., y Seidel, M. (2006). Los Mayas: Una civilización milenaria. Colonia: Könemann.

Westheim, P. (1988). Arte antiguo de México. México: Alianza Editorial Era.

Westheim, P. (1987). Ideas fundamentales del arte prehispánico en México. México: Alianza Editorial Era.

Wilkinson, P. (2009). Mitos y leyendas. México: DK. 